\title{
Response to first line chemotherapy regimen is associated with efficacy of Immune Checkpoint Blockade Therapies in Patients with Metastatic Urothelial Carcinoma
}

\section{Deniz Tural ( $\square$ deniztural@gmail.com )}

Istanbul Bakirkoy Dr Sadi Konuk Egitim ve Arastirma Hastanesi https://orcid.org/0000-0003-21446469

\section{Fatih Selçukbiricik}

Koç Üniversitesi: Koc Universitesi

Ömer Fatih Ölmez

Istanbul Medipol University: Istanbul Medipol Universitesi

Ahmet Taner Sümbül

Başkent Üniversitesi: Baskent Universitesi

\section{Mustafa Erman}

Hacettepe University: Hacettepe Universitesi

\section{Hasan Şenol Coşkun}

Akdeniz Üniversitesi: Akdeniz Universitesi

\section{Mehmet Artaç}

Necmettin Erbakan Üniversitesi Meram Tıp Fakültesi: Necmettin Erbakan Universitesi Meram Tip

Fakultesi

\section{Saadettin Kılıçkap}

İstinye Üniversitesi: Istinye Universitesi

\section{Research Article}

Keywords: Atezolizumab, Urothelial Carcinoma, Bladder Cancer, Chemotherapy, Immunotherapy, Outcomes

Posted Date: July 19th, 2021

DOl: https://doi.org/10.21203/rs.3.rs-712822/v1

License: (c) (1) This work is licensed under a Creative Commons Attribution 4.0 International License. Read Full License 
Version of Record: A version of this preprint was published at International Journal of Clinical Oncology on November 11th, 2021. See the published version at https://doi.org/10.1007/s10147-021-02072-x. 


\section{Abstract \\ Background}

Atezolizumab (ATZ) has demonstrated antitumor activity in the previous studies in patients with metastatic platinum-resistant urothelial carcinoma. However, the response rate of ATZ was modest. Therefore, finding biologic or clinical biomarkers that could help to select patients who respond to the immune checkpoint blockade remains important.

\section{Patients and Methods}

In this study, we present the retrospective analysis of 105 patients with urothelial cancer treated with ATZ after progression on first-line chemotherapy. Data of patients were obtained from patient files and hospital records. The association between response to first-line chemotherapy and ATZ was using Fisher's exact test. Median follow-up was calculated using the reverse Kaplan-Meier method. OS was estimated by using the Kaplan-Meier method.

\section{Results}

The median follow-up time was 23.5 months. Forty (74.1\%) of patients who experienced clinical benefit after firs-line chemotherapy also had clinical benefit after atezolizumab, while only $14(25.9 \%)$ of patients with initial PD after first-line chemotherapy subsequently experience clinical benefit with ATZ $(p=0.001)$. The median OS on ATZ of 14.8 and 3.4 months for patients with clinical benefit and progressive disease in response to first-line chemotherapy, respectively $(p=0.001)$. Three of the adverse prognostic factors according to the Bellmunt criteria were independent factors of short survival: liver metastases (Hazard Ratio $[H R]=1.9 ; p=0.04), E C O G P S \geq 1(H R=2.7 ; p=0.001)$, and Hemoglobin level below $10 \mathrm{mg} / \mathrm{dl}(\mathrm{HR}=$ 2.8; $p<0.001)$. In addition, patients with clinical benefit from first-line chemotherapy $(H R=0.39 ; p<0.001)$ maintained a significant association with OS in multivariate analysis.

\section{Conclusions}

Our study demonstrated that clinical benefit from first-line chemotherapy was independent prognostic factors on OS in patients' use of ATZ as second-line treatment in metastatic bladder cancer. Furthermore, these findings are important for stratification factors for future immunotherapy study design in patients with bladder cancer who have progressed after first-line chemotherapy

\section{Introduction}

Urothelial carcinoma, which is the ninth most common tumor worldwide, is an aggressive malignancy with a five-year survival rate of about $5 \%$ in the metastatic setting [1, 2]. The standard first-line treatment 
in the metastatic urothelial carcinoma setting is cisplatin-based chemotherapy. Cisplatin-based chemotherapy-related objective response rates (ORR), disease control rates (DCR) and median overall survival (OS) times range between $40-50 \%, 75-80 \%$, and 14 to 15.2 months, respectively [3]. Patients who relapse following cisplatin-based chemotherapy have a poor prognosis with median overall survival times ranging from 5 to 7 months [4].

In recent years, effective antitumor activity has been reported in association with the use of several immune checkpoint inhibitors targeting the programmed cell death protein 1 (PD-1) receptor and its ligand (PD-L1) during the course of first-line therapy or second-line therapy in metastatic urothelial carcinoma patients [5]. The antitumor activity of atezolizumab, one of these immune checkpoint inhibitors, has been demonstrated to have manageable safety in patients with locally advanced or metastatic platinum-resistant urothelial carcinoma [6-9]. Nevertheless, the reported ORRs associated with the use of atezolizumab as the second-line therapy in locally advanced and metastatic setting urothelial carcinoma patients range between $15 \%$ and $28.7 \%$ [6-9]. Therefore, it is important to identify the factors associated with acceptable efficacy levels of immune checkpoint inhibitors.

In this context, according to the Bellmunt criteria, three risk factors have been determined to predict overall survival (OS) in patients with platinum-refractory disease during second-line treatment. These risk factors are; Eastern Cooperative Oncology Group (ECOG) Performance Status, hemoglobin levels and liver metastases [10]. However, it is unclear whether these factors can be used to predict the efficacy of checkpoint inhibitors in patients with metastatic platinum-resistant urothelial carcinoma. There is still not any generally accepted biomarker indicated for use in patients with metastatic platinum-resistant urothelial carcinoma to predict the efficacy of checkpoint inhibitors. Thus, it is very important to find optimal predictive biomarkers in patients with advanced urothelial carcinoma that receive checkpoint inhibitors including atezolizumab.

There are studies in the literature in which cross-resistance was demonstrated between the chemotherapy regimens received as the first-line and the second-line therapy in metastatic urothelial carcinoma patients. However, given the fact that chemotherapy agents may also affect the immune checkpoint blockade responses in addition to their capacity to directly kill tumor cells, there are not enough studies conducted on the cross-resistance between the immune checkpoint inhibitors and chemotherapy regimens $[11,12]$. Accordingly, it may be possible to improve cytotoxic chemotherapy on the basis of the antitumor immune response.

In view of the foregoing, in this study, patients' responses to the first-line treatment were assessed in the context of immunotherapy checkpoint blockade in patients with metastatic urothelial carcinoma. Accordingly, patients' responses to the first-line treatment were assessed in terms of use as a clinical biomarker to predict the objective response rates and overall survival times in metastatic urothelial carcinoma patients receiving atezolizumab as the second-line treatment.

\section{Material And Method}


The research data of 140 metastatic urothelial carcinoma patients were collected from the hospital records and patient files, and were then analyzed retrospectively. Of these patients, 126 were determined to have received at least one cycle of atezolizumab treatment. The data of 21 patients were not available. Consequentially, data of 105 patients that received at least one cycle of atezolizumab treatment as the second-line treatment following the disease progression despite first-line treatment were analyzed within the scope of the study.

In this context, responses to the first-line treatment and to atezolizumab as the second-line treatment, were retrospectively assessed on the basis of the relevant computed tomography data recorded every 12 weeks, according to Response Evaluation Criteria in Solid Tumors (RECIST) version 1.1. Responses to the treatments were determined by the data collector on the basis of the relevant radiographic and clinical data. The respective analysis did not include a central evaluation carried out by a blinded radiologist according to RECIST version 1.1 criteria. Clinical benefit rates (CBR) were classified under three categories according to best responses exhibited by the patients, which are; cases with complete response to treatment, cases with partial response to treatment and cases with no response to treatment (stable disease). The relation between response to the first-line treatment and to atezolizumab was assessed using the Fisher's exact test. Median follow-up times were calculated using the reverse Kaplan-Meier method. Overall Survival (OS) times were estimated using the Kaplan-Meier method. OS time was defined as the time elapsed from the administration of the first dose of atezolizumab till death for any reason. OS times were censored as of the date of last information and were thus estimated using the Kaplan-Meier method. Exact $95 \%$ confidence intervals $(\mathrm{Cl})$ were used in the statistical analyses.

Univariate analysis was used to identify the clinical factors and laboratory parameters with a significant effect on OS. The variables that were found to have a statistical relationship with OS were analyzed within the scope of multivariate analysis ( $p \otimes 0.1)$. Subsequently, the variables in respect of which the associated probability $(p)$ values were found to be less than 0.05 were included in the final model. All statistical analyses were performed using the SPSS Statistics 23.0 (Statistical Package for Social Sciences version 23.0, IBM Corporation, USA) software package. The study was approved by the local ethics committee with approval no 2019-291.

\section{Results}

Of the 105 patients that were determined to have met the inclusion criteria, 90 (85.7\%) were male and 15 (14.3\%) were female. The median age of the patients was 65 years (min.: 37 and max.: 86 ). The median follow-up time was 23.5 months. It was determined that $5(4.8 \%)$ patients exhibited complete response (CR) to the first-line treatment, that $38(36.2 \%)$ patients exhibited partial response (PR) to the first-line treatment, that $16(15.2 \%)$ patients had stable disease (SD) following the first-line treatment, and that 46 $(43.8 \%)$ patients had progressive disease (PD) following the first-line treatment. Additionally, it was determined that $9(8.6 \%)$ patients exhibited CR to the second-line treatment (atezolizumab), that 22 (21\%) patients exhibited PR to the second-line treatment, that 23 (21.9\%) patients had stable disease (SD) following the second-line treatment, and that 51 (48.5\%) patients had progressive disease (PD) following 
the second -line treatment. Of the patients that received first-line treatment, $87(83 \%)$ patients received second-line treatment in the form of atezolizumab in 3 months time or even before then as a result of disease progression following the first-line treatment. Forty-four percent (44\%) of the patients received carboplatin-based chemotherapy. Patients' characteristics are shown in Table 1. Forty (74.1\%) patients who were clinically benefited from the first-line treatment were determined to have also benefited from the atezolizumab treatment, whereas only $14(25.9 \%)$ patients with disease progression after first-line treatment were determined to have also benefited from the ensuing atezolizumab treatment (Fisher's exact test, $p=0.001$ ).

At the time of the analysis, the median OS of the patients treated with atezolizumab was determined to be 10 months (95\% Cl; 7-13.1 months) (Fig. 1). OS times of the patients calculated by taking the start of the atezolizumab treatment as the baseline were significantly different than the OS times of the patients calculated by taking the time of the best response given to the first-line treatment as the baseline. Patients who were clinically benefited from first-line treatment had higher OS times. The median OS calculated by taking the start of the atezolizumab treatment as the baseline was determined as 14.8 months in case of patients who were clinically benefited from the first-line treatment and as 3.4 months in case of patients who had a disease progression following the first-line treatment (log-rank $p=0.001$ ) (Fig. 2). Univariate analysis revealed that parameters such as liver metastases, baseline creatinine clearance (GFR-glomerular filtration rate) less than $60 \mathrm{ml} / \mathrm{min}$, Eastern Cooperative Oncology Group (ECOG) performance status $\geq 1$, and hemoglobin levels below $10 \mathrm{mg} / \mathrm{dl}$ were all significantly associated with OS in case of patients who were clinically benefited from the first-line treatment. The distribution of the OS times by all clinical subgroups as of the start of the atezolizumab treatment are shown in Table 2. According to the Bellmunt criteria, three of the adverse prognostic factors were determined to be independent factors of short-term survival, which are liver metastases $(H R=1.9 ; 95 \% \mathrm{Cl} 1.0-3.7 ; p=0.04)$, ECOG PS $\geq 1(\mathrm{HR}=2.7 ; 95 \% \mathrm{Cl} 1.5-4.9 ; \mathrm{p}=0.001)$, and Hemoglobin hemoglobin levels below $10 \mathrm{mg} / \mathrm{dl}$ $(\mathrm{HR}=2.8 ; 95 \% \mathrm{Cl} 1.7-4.5 ; p<0.001)$. Additionally, multivariate analysis also revealed a significant relationship between the OS of the patients and the clinical benefit they derived from the first-line treatment $(\mathrm{HR}=0.39 ; 95 \% \mathrm{Cl} 0.24-0.65 ; p<0.001)$ (Table 3$)$.

\section{Discussion}

The findings of this study indicated a significant relationship between the clinical benefit derived from the first-line treatment in patients with metastatic urothelial carcinoma and the clinical benefit derived from the atezolizumab treatment administered to these patients as the second-line treatment. Additionally, it was also determined that the patients who were clinically benefited from the first-line treatment had significantly longer overall survival times calculated by taking the start of the atezolizumab treatment as the baseline. These findings are very important in that they can be utilized as stratification factors in immunotherapy studies to be conducted on bladder cancer patients with disease progression following first-line treatment. 
In the Javelin bladder 100 trial, a study of avelumab in patients with locally advanced or metastatic urothelial cancer, it was demonstrated that the patients who had non-progressive advanced urothelial carcinoma following the first-line platinum-based chemotherapy had significantly longer OS times following the administration of avelumab therapy as the maintenance therapy not later than 10 weeks after the completion of the first-line treatment, as compared to the patients that were provided the best supportive care [13]. In parallel to the results of the said trial, administration of avelumab therapy as the maintenance therapy has been accepted as the standard treatment protocol for patients who were clinically benefited from the platinum-based chemotherapy. The Javelin bladder 100 trial also revealed that the patients with advanced urothelial cancer were clinically benefited from the avelumab therapy, irrespective of whether they received cisplatin or carboplatin as the first-line treatment.

In comparison, in this study, from among the patients that received first-line treatment, 87 (83\%) patients received second-line treatment in the form of atezolizumab in 3 months time or even before then as a result of disease progression following the first-line treatment, and forty-four percent (44\%) of the patients received carboplatin-based chemotherapy. Similar to the findings reported in the Javelin bladder 100 trial, in this study as well, no significant differences were found between the OS and the type of the chemotherapy administered and the period elapsed between the completion of the chemotherapy as the first-line treatment and the initiation of atezolizumab therapy as the second-line treatment.

CBRs of the patients that received cisplatin-based chemotherapy were calculated between $75-80 \%$, nevertheless nearly $50 \%$ of the patients who had metastatic urothelial carcinoma were not eligible to receive cisplatin-based chemotherapy $[3,4]$. ORRs of the patients that were not eligible to receive cisplatin-based chemotherapy were around $40 \%$, and lower than the ORRs of the patients that were eligible to receive cisplatin-based chemotherapy [14]. Therefore, many patients who have metastatic urothelial cancer do not actually meet the required eligibility criteria to receive avelumab therapy as the maintenance treatment.

In comparison, in this study, CBRs of the patients with metastatic urothelial cancer that received the firstline treatment was calculated as $56.2 \%$. Forty $(74.1 \%)$ patients, who were determined to have clinically benefited from the first-line treatment, were found to have clinically benefited from the atezolizumab treatment as well. On the other hand, only fourteen (25.9\%) patients with a disease progression following the first-line treatment were found to have clinically benefited from the atezolizumab treatment.

Therefore, in this study, unlike the Javelin bladder 100 trial, a group of stage IV bladder cancer patients, who were determined not to have clinically benefited from chemotherapy as the first-line treatment, were found to have benefited from the immune checkpoint inhibitors blockade treatment as the second-line treatment.

In the INDUCOMAIN study, it was demonstrated that the stand-alone use of immune checkpoint inhibitors prior to induction chemotherapy is not an adequate strategy, since it was found that the use of said strategy led to more frequent early disease progression [15]. In comparison, in this study, as was the case in the Javelin bladder 100 trial, use of chemotherapy immune checkpoint inhibitors was demonstrated to 
be a good treatment option for metastatic urothelial carcinoma following the administration of induction chemotherapy [13]. Additionally, initial chemotherapy could potentially induce immunogenic cell death or depletion of suppressive immune cell populations such as myeloid-derived suppressor cells, thereby enhancing the effect of subsequently administered checkpoint inhibitors [16].

There were some limitations to this study. First, it was carried out as a retrospective study. Thus, responses to the treatments had to be determined by the data collector on the basis of the relevant radiographic and clinical data, and the respective analyses did not include a central evaluation carried out by a blinded radiologist according to RECIST criteria. Secondly, there were some potential confounder variables.

\section{Conclusion}

It was concluded based on the findings of this study that the clinical benefit derived from the first-line treatment is an independent prognostic factor on OS in metastatic bladder cancer patients that received atezolizumab as the second-line treatment. Additionally, a group of stage IV bladder cancer patients, who were determined not to have clinically benefited from chemotherapy as the first-line treatment, were found to have benefited from the immune checkpoint inhibitors blockade treatment as the second-line treatment. Consequentially, the findings of this study can be utilized to develop the necessary stratification factors in immunotherapy studies to be conducted on bladder cancer patients with disease progression following the first-line treatment.

\section{Declarations}

There is no conflict of interest in connection with the publication of this manuscript. As the corresponding author, I declare on my own behalf that this study constitutes an original research, that is, it has not been published previously in any form and it is not under consideration for publication elsewhere, either in whole or in part. All the authors listed have approved the enclosed manuscript for publication. All authors have contributed to the collection of the research data, analyses of these data, compilation and presentation of the respective research findings in the form of an article.

\section{References}

1. Ferlay J, Soerjomataram I, Dikshit R et al (2015) Cancer incidence and mortality worldwide: sources, methods and major patterns in GLOBOCAN 2012. Int J Cancer 136:E359-E386

2. National Cancer Institute Surveillance, Epidemiology, and End Results Program. SEER cancer statistics factsheets: Bladder cancer. https://seer.cancer.gov/statfacts/html/urinb.html(accessed Dec 10, 2019)

3. von der Maase H, Sengelov L, Roberts JT et al (2005) Long-term survival results of a randomized trial comparing gemcitabine plus cisplatin, with methotrexate, vinblastine, doxorubicin, plus cisplatin in patients with bladder cancer. J Clin Oncol 23:4602-4608 
4. Bellmunt J, Théodore C, Demkov T et al (2009) Phase III trial of vinflunine plus best supportive care compared with best supportive care alone after a platinum-containing regimen in patients with advanced transitional cell carcinoma of the urothelial tract. J Clin Oncol 27:4454-4461

5. Bellmunt J, Powles T, Vogelzang NJ (2017) A review on the evolution of PD-1/PD-L1 immunotherapy for bladder cancer: The future is now. Cancer Treat Rev 54:58-67

6. Rosenberg JE, Hoffman-Censits J, Powles T et al (2016) Atezolizumab in patients with locally advanced and metastatic urothelial carcinoma who have progressed following treatment with platinum-based chemotherapy: a single-arm, multicentre, phase 2 trial. Lancet. May 7;387(10031):1909-20

7. Powles T, Durán I, van der Heijden MS,et al. Atezolizumab versus chemotherapy in patients with platinum-treated locally advanced or metastatic urothelial carcinoma (IMvigor211): a multicentre, open-label, phase 3 randomised controlled trial. Lancet. 2018 Feb 24;391(10122):748-757

8. Sternberg CN, Loriot Y, James N et al (2019 Jul) Primary Results from SAUL, a Multinational Singlearm Safety Study of Atezolizumab Therapy for Locally Advanced or Metastatic Urothelial or Nonurothelial Carcinoma of the Urinary Tract. Eur Urol 76(1):73-81

9. Tural D, Olmez OF, Sumbul AT et al. Atezolizumab in patients with metastatic urothelial carcinoma who have progressed after first-line chemotherapy: Results of real-life experience. Eur Urol Focus. 2020: S2405-4569(20)30269-8

10. BellmuntJ AlbanellJ, Paz-AresL et al (2002) Pretreatment prognostic factors for survival in patients with advanced urothelial tumors treated in a phase I/II trial with paclitaxel, cisplatin, and gemcitabine. Cancer 95(4):751-757

11. Grivas P, Monk BJ, Petrylak D et al (2019) Immune Checkpoint Inhibitors as Switch or Continuation Maintenance Therapy in Solid Tumors: Rationale and Current State. Target Oncol 14:505-525

12. Szabados B, van Dijk N, Tang YZ,et al (2018) Response Rate to Chemotherapy After Immune Checkpoint Inhibition in Metastatic Urothelial Cancer. Eur Urol 73:149-152

13. Powles T, Park SH, Voog E et al (2020) Avelumab Maintenance Therapy for Advanced or Metastatic Urothelial Carcinoma. N Engl J Med 383:1218-1230

14. De Santis M, Bellmunt J, Mead G,et al (2012) Randomized phase II/III trial assessing gemcitabine/carboplatin and methotrexate/carboplatin/vinblastine in patients with advanced urothelial cancer who are unfit for cisplatin-based chemotherapy: EORTC study 30986. J Clin Oncol 30:191-199

15. Valderrama BP, Castellano D, Marín ÁP et al. Phase II multicenter, randomized study to evaluate efficacy and safety of avelumab with carboplatin/gemcitabine (CG) vs CG alone in patients with unresectable or metastatic urothelial carcinoma ( $\mathrm{mUC}$ ) who are ineligible to receive cisplatin-based therapy ("INDUCOMAIN").ESMO 2020 virtual congress

16. Hato SV, Khong A, de Vries IJ et al (2014) Molecular pathways: The immunogenic effects of platinum-based chemotherapeutics. Clin Cancer Res 20:2831-2837 


\section{Tables}

Page 10/17 


\begin{tabular}{|c|c|c|}
\hline Table-1: Patient Characteristics & $\mathrm{n}$ & $\%$ \\
\hline Median age (years) & \multicolumn{2}{|c|}{65 (Min.:37; Max.: 86) } \\
\hline Gender (male) & 90 & 85.7 \\
\hline \multicolumn{3}{|l|}{ Site of Primary Tumor } \\
\hline Bladder & 92 & 87.6 \\
\hline Upper Tract & 13 & 12.4 \\
\hline \multicolumn{3}{|l|}{ ECOG-PS } \\
\hline 0 & 27 & 25.7 \\
\hline 1 & 74 & 70.5 \\
\hline 2 & 4 & 3.8 \\
\hline \multicolumn{3}{|l|}{$<60 \mathrm{ml} / \mathrm{min}$} \\
\hline \multicolumn{3}{|l|}{$<10 \mathrm{~g} / \mathrm{dl}$} \\
\hline \multicolumn{3}{|l|}{ Smoking Status } \\
\hline Current smoker & 27 & 25.7 \\
\hline Ex-smoker & 53 & 50.5 \\
\hline Never smoker & 25 & 23.8 \\
\hline \multicolumn{3}{|l|}{ Metastatic Site at Baseline } \\
\hline Visceral & 84 & 80 \\
\hline Liver & 16 & 15.2 \\
\hline Lymph Node Only & 15 & 14.3 \\
\hline \multicolumn{3}{|l|}{ Number of Bellmunt Risk Factors } \\
\hline 0 & 19 & 18 \\
\hline 1 & 55 & 52.4 \\
\hline 2 & 26 & 24.8 \\
\hline 3 & 5 & 4.8 \\
\hline Metastatic at the time of diagnosis & 45 & 42.9 \\
\hline Neoadjuvant Chemotherapy & 21 & 20 \\
\hline
\end{tabular}

Page $11 / 17$ 


\begin{tabular}{|c|c|c|}
\hline Pelvic Radiotherapy & 33 & 31.4 \\
\hline Cystectomy & 43 & 41 \\
\hline \multicolumn{3}{|l|}{ Previous Chemotherapy } \\
\hline Cisplatin-based & 59 & 56 \\
\hline Carboplatin-based & 46 & 44 \\
\hline \multicolumn{3}{|c|}{ Best response to first-line treatment } \\
\hline Complete response (CR) & 5 & 4.8 \\
\hline Partial response (PR) & 38 & 36.2 \\
\hline Stable disease (SD) & 16 & 15.2 \\
\hline Progressive disease (PD) & 46 & 43.8 \\
\hline \multicolumn{3}{|c|}{ Time elapsed since the last chemotherapy } \\
\hline 3 months $\geq$ & 18 & 17 \\
\hline 3 months $\rrbracket$ & 87 & 83 \\
\hline
\end{tabular}

Abbreviations: Min.: Minimum; Max.: Maximum; ECOG-PS: Eastern Cooperative Oncology GroupPerformance Status 


\begin{tabular}{|c|c|c|c|}
\hline \multicolumn{4}{|l|}{ Table-2 } \\
\hline Patient sub-groups & OS (months) & $\% 95 \mathrm{Cl}$ & $p$ \\
\hline All patients & 10 & 7-13.1 & $\mathrm{N} / \mathrm{A}$ \\
\hline \multicolumn{4}{|c|}{ Best response to first-line treatment } \\
\hline$C R+P R+S D$ & 14.8 & 8.3-21.4 & 0.001 \\
\hline PD & 3.4 & $0.5-6.4$ & \\
\hline \multicolumn{4}{|l|}{ Age (years) } \\
\hline$\leq 65$ & 8.7 & $4.2-13.1$ & \multirow[t]{2}{*}{0.7} \\
\hline$>65$ & 10 & $5.9-14.2$ & \\
\hline \multicolumn{4}{|l|}{ Gender } \\
\hline Male & 9.8 & $6.9-12.7$ & \multirow[t]{2}{*}{0.5} \\
\hline Female & 11.9 & $4.2-19.6$ & \\
\hline \multicolumn{4}{|l|}{ Smoking Status } \\
\hline Yes & 10.2 & $6.9-13.5$ & \multirow[t]{2}{*}{0.9} \\
\hline No & 7.72 & $1.9-13.6$ & \\
\hline \multicolumn{4}{|c|}{ Location of the Tumor } \\
\hline Upper tract & 5.1 & $2.7-7.4$ & \multirow[t]{2}{*}{0.14} \\
\hline Bladder & 10.3 & $6.9-13.6$ & \\
\hline \multicolumn{4}{|l|}{ ECOG-PS } \\
\hline 0 & 18.4 & $14.5-22.3$ & \multirow[t]{2}{*}{0.002} \\
\hline $1 \geq$ & 8.1 & $4.2-12$ & \\
\hline \multicolumn{4}{|c|}{ Baseline Creatinine Clearance } \\
\hline$<60 \mathrm{ml} / \mathrm{min}$ & 4.4 & $2.4-6.3$ & \multirow[t]{2}{*}{0.008} \\
\hline$\geq 60 \mathrm{ml} / \mathrm{min}$ & 14.5 & 8.3-20.8 & \\
\hline \multicolumn{4}{|c|}{ Baseline Hemoglobin concentration } \\
\hline$<10 \mathrm{~g} / \mathrm{dl}$ & 3.5 & $1.5-6.1$ & \multirow[t]{2}{*}{0.001} \\
\hline$\geq 10 \mathrm{~g} / \mathrm{dl}$ & 13.4 & $8.5-18.2$ & \\
\hline \multicolumn{4}{|c|}{ Metastatic at the time of diagnosis } \\
\hline Yes & 8.4 & $5.8-11.9$ & 0.3 \\
\hline
\end{tabular}




\begin{tabular}{|c|c|c|c|}
\hline No & 10.8 & $5.27-15.2$ & \\
\hline \multicolumn{4}{|c|}{ Lymph Node Only Metastasis } \\
\hline Yes & 14.5 & $3-26$ & \multirow[t]{2}{*}{0.2} \\
\hline No & 8.5 & $5.6-11.4$ & \\
\hline \multicolumn{4}{|c|}{ Visceral Metastasis } \\
\hline Yes & 8.7 & $5.1-12.3$ & \multirow[t]{2}{*}{0.7} \\
\hline No & 11.8 & $6.8-16.9$ & \\
\hline \multicolumn{4}{|c|}{ Liver Metastasis } \\
\hline Yes & 1.4 & $0.7-2.7$ & \multirow[t]{2}{*}{0.001} \\
\hline No & 11.4 & $7.8-14.9$ & \\
\hline \multicolumn{4}{|c|}{ Number of Bellmunt Risk Factors } \\
\hline 0 & 20.2 & $16-24.3$ & \multirow[t]{4}{*}{0.001} \\
\hline 1 & 14.2 & $11.4-16.9$ & \\
\hline 2 & 6 & $3.6-8.5$ & \\
\hline 3 & 1.2 & $0.6-1.9$ & \\
\hline \multicolumn{4}{|c|}{ Cystectomy } \\
\hline Yes & 10.6 & $4.6-17$ & \multirow[t]{2}{*}{0.3} \\
\hline No & 9.7 & $7.9-12.1$ & \\
\hline \multicolumn{4}{|c|}{ Neoadjuvant Chemotherapy } \\
\hline Yes & 9.8 & $3-16.7$ & \multirow[t]{2}{*}{0.5} \\
\hline No & 9.7 & $6.4-13$ & \\
\hline \multicolumn{4}{|c|}{ Radiotherapy (Palliative/Curative) } \\
\hline Yes & 13.4 & $4-22.8$ & \multirow[t]{2}{*}{0.16} \\
\hline No & 8.2 & $5.8-10.6$ & \\
\hline
\end{tabular}

Time elapsed since the last chemotherapy

3 months>

4.8-20.1

0.35

$5.8-13.6$
Abbreviations: OS: Overall Survival; Cl: Confidence Interval; p: probability; CR: Complete response; PR:Partial response; SD:Stable disease; PD: Progressive disease; ECOG-PS: Eastern Cooperative Oncology Group-Performance Status 


\begin{tabular}{|c|c|c|c|}
\hline \multicolumn{4}{|l|}{ Table-3 } \\
\hline Patient sub-groups & $H R$ & $95 \% \mathrm{Cl}$ & $p$ \\
\hline \multicolumn{4}{|l|}{ ECOG-PS } \\
\hline$\geq 1$ & 2.7 & $1.5-4.9$ & 0.001 \\
\hline \multicolumn{4}{|c|}{ Clinical benefit from the first-line treatment } \\
\hline Yes & 0.39 & $0.24-0.65$ & $<0.001$ \\
\hline \multicolumn{4}{|c|}{ Baseline Hemoglobin concentration } \\
\hline$<10 \mathrm{gr} / \mathrm{dl}$ & 2.680 & $1.558-4.608$ & $<0.001$ \\
\hline \multicolumn{4}{|l|}{ Liver Metastasis } \\
\hline Yes & 1.9 & $1.0-3.7$ & 0.04 \\
\hline
\end{tabular}

Abbreviations: HR: Hazard Ratio; Cl: Confidence Interval; p: probability; ECOG-PS: Eastern Cooperative Oncology Group-Performance Status

\section{Figures}




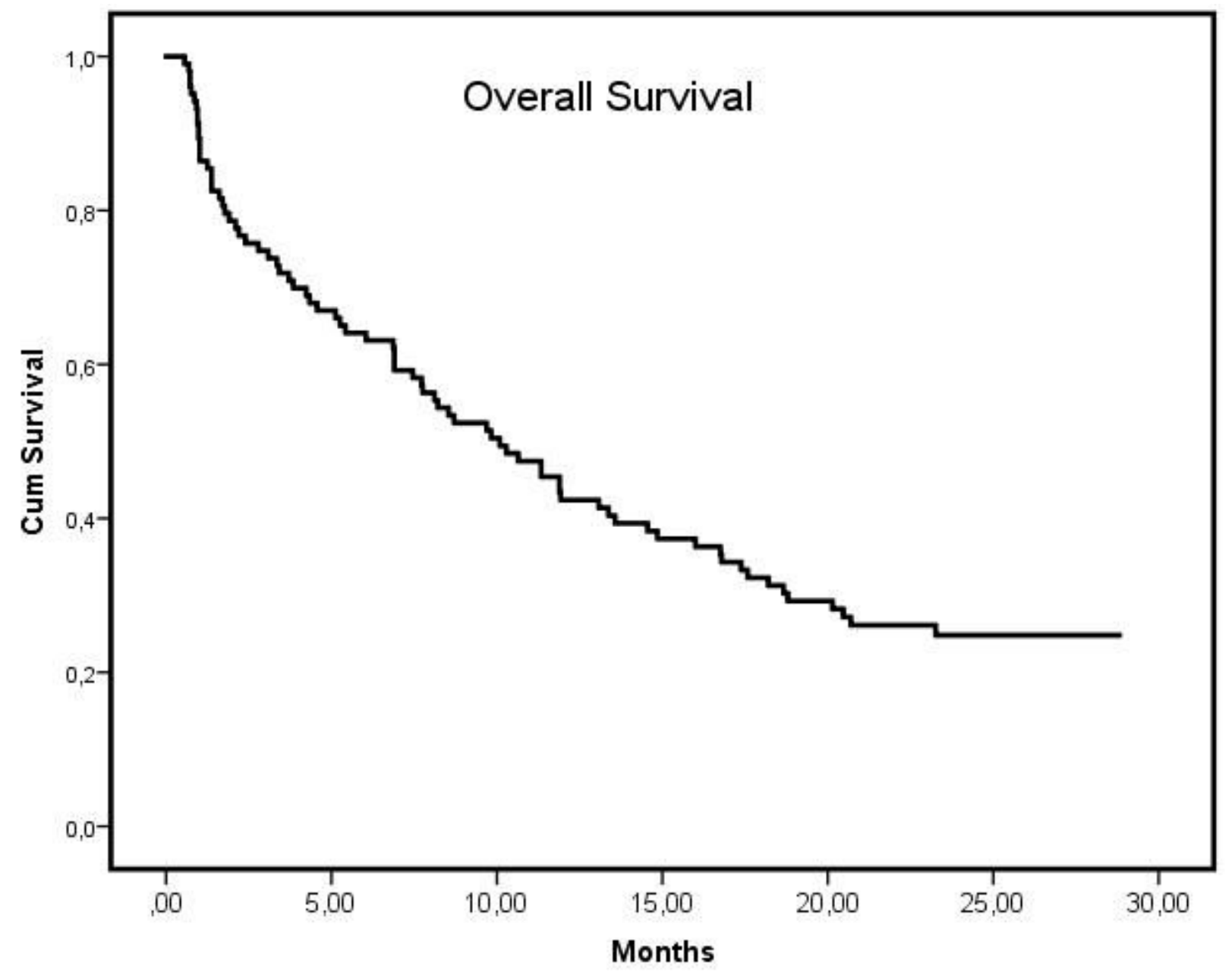

Figure 1

Kaplan-Meier curves for overall survival 


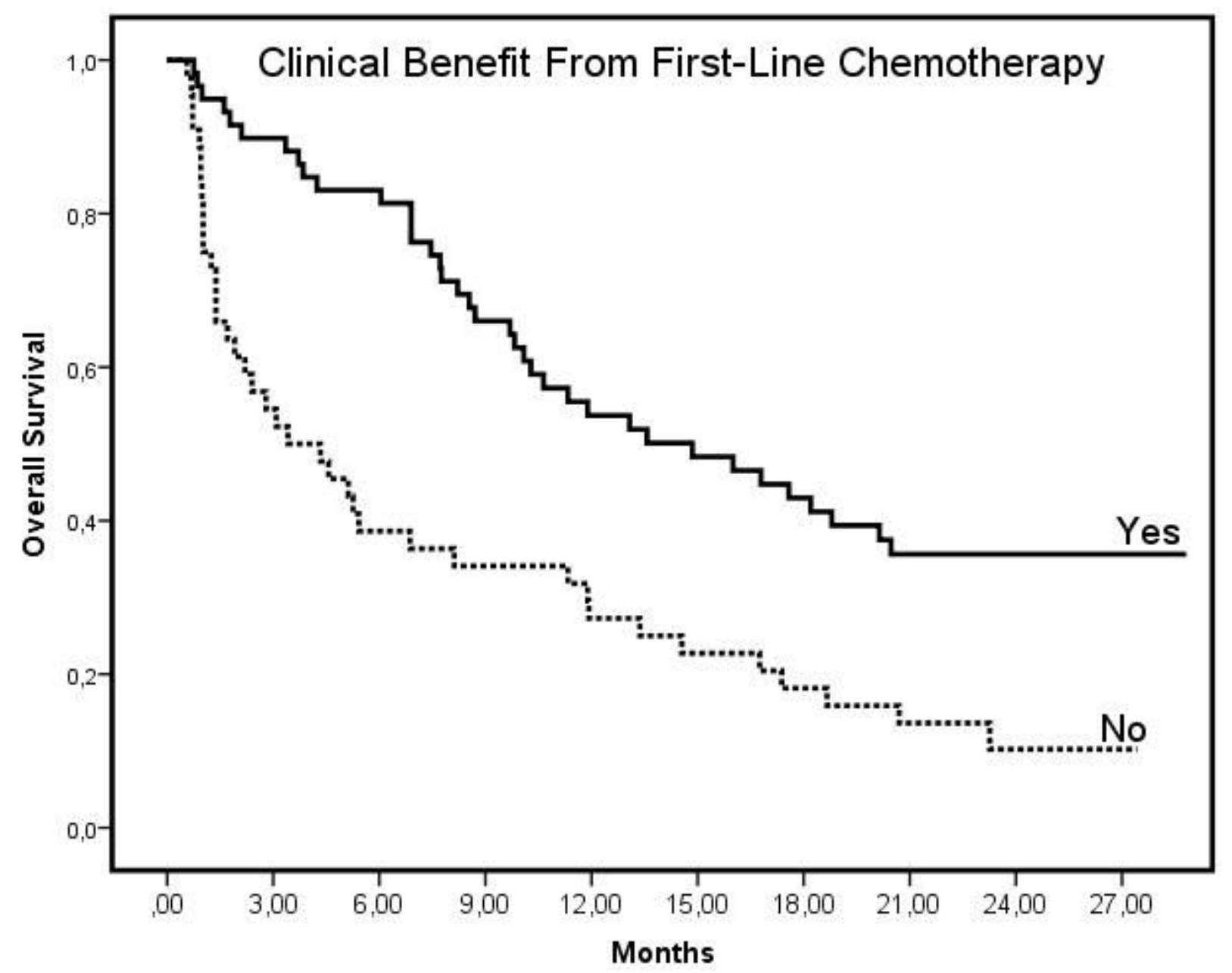

Figure 2

Kaplan-Meier curves association of clinically benefited from the first-line treatment and overall survival 